\title{
Estudio comparativo de la administración de darbepoetina pre versus post-hemodiálisis
}

\author{
$M^{\text {a }}$ Teresa López Alonso, Herminia Martí Centelles, Azucena Barranco Sos, Nuria Ribas Cortada, Valentín \\ Lozano Molero, Marta Quintela Martínez
}

\section{Hospital Clínic. Barcelona}

\section{Introducción:}

La administración de agentes estimuladores de la eritropoyesis ( $A E E)$, en el tratamiento de la anemia en la enfermedad renal crónica (ERC), ha mejorado los niveles de hemoglobina $(\mathrm{Hb})$ y hematocrito ( $\mathrm{Hto}$. ), tanto los de acción media como los de vida más larga, que permiten intervalos de dosificación más prolongados. Habitualmente se administran postdiálisis (post) en la desconexión, en la línea venosa. Sin embargo, dado que la molécula que utilizamos es darbepoetina, con un peso molecular elevado (37.1kDa), teóricamente no se dializa, podríamos administrarla al inicio de la hemodiálisis.

\section{Objetivo:}

Comparar la efectividad en el tratamiento de la anemia de la administración prediálisis (pre) de darbepoetina, respecto a la clásica administración postdiálisis. Valorar la repercusión en trabajo de enfermería.

\section{Pacientes y método:}

Estudio randomizado y cruzado. Incluimos 81 pacientes; 56 hombres, 25 mujeres, con una edad media de $62,4 \pm 15$ años (28-87) con dosis de darbepoetina post, estables, sin sangrado activo ni tratamiento de quimioterapia o inmunosupresores. No precisó extracciones adicionales. La analítica basal fue la del último mes en la que todos los pacientes estaban recibiendo darbepoetina postdiálisis, posteriormente se utilizó la analítica mensual rutinaria. El periodo de seguimiento fue de doce meses en los que se varió la administración de darbepoetina de la siguiente manera: Grupo A (PRE-POST): después de la determinación basal, se administró trimestralmente: pre, post, pre, post. Grupo B (POST-PRE): después de la determinación basal se administró trimestralmente: post, pre, post, pre. Determinamos mensualmente los valores de hemoglobina $(\mathrm{Hb})$, hematocrito $(\mathrm{Hto})$, volumen corpuscular medio (VCM), índice de saturación de la transferrina (IST) y ferritina. Se recogió la dosis de darbepoetina y hierro endovenoso y parámetros de diálisis: peso seco, litros convectivos (L) y Kt. Se pasó una encuesta al personal de enfermería sobre la preferencia de administración de los $A E E$, con tres opciones: pre, post, indiferente.

\section{Resultado:}

Los valores de $\mathrm{Hb}$ basal fueron $11,59 \pm 13$ y $11,32 \pm$ 12 en los grupos $A$ y $B$ respectivamente, se mantuvieron sin cambios significativos durante el periodo de seguimiento. Los valores de ferritina, IST, PCR, VCM y HTO, no observaron diferencias con significación estadística. Las dosis de darbepoetina basal fue de 45,0 $\pm 32 \mathrm{mcg} /$ semana en el grupo A y $35,1 \pm 25 \mathrm{mcg} /$ semana en el grupo $B$. Si se observó una reducción no significativa de la dosis en el grupo $A$, mientras que en el grupo $B$ se mantuvo estable. La dosis de hierro endovenoso no varió significativamente en ambos grupos. No hubo diferencias en los parámetros de diálisis: peso seco, L, Kt. En la encuesta de enfermería, la preferencia de administración fue: pre $86 \%$, post $10 \%$, indiferente $4 \%$. 


\section{Conclusión:}

En el control de la anemia en los pacientes en hemodiálisis, la administración de darbepoetina prediálisis es equivalente a la administración postdiálisis. En la encuesta de enfermería sobre la preferencia de administración, la opción pre fue elegida por el $86 \%$. Como resultado de este trabajo y consensuado con el equipo médico, se decidió cambiar la administración de darbepoetina a pre.

\section{Referencias Bibliográficas}

1. Nefrologia Clínica $4^{\mathrm{a}}$ edición en imprenta, capítulo 66.4 Anemia y alteraciones de la coagulación renal crónica. Dr Aleix Cases. Maduell F. Optimizing the prescription of hemodiafiltration. Contrib Nephrol. Basel, Karger, 158: 225-231, 2007.

2. Nefrología. Vol XXIII. Número 2. 2003 A. Martínez Castelao. Revista de SEDEN . Volumen $11 n^{\circ}$ 3/ julio-septiembre 2008 Eficacia del tratamiento con r-HuEPO, al inicio o final de la sesión, en hemodiálisis convencional y "On-Line". E. Melero Rubio. Maduell F: Hemodiafiltration. Hemodial Int 9: 47-55, 2005. 